\title{
Gender gaps in child nutrition in Malawi: Does cultural
}

\section{lineage matter? [version 1; peer review: 2 approved, 1}

\section{approved with reservations]}

\author{
Martin Limbikani Mwale (D1), Tony Mwenda Kamninga (D)2, Lucius Cassim (Did) \\ ${ }^{1}$ Department of Economics, Stellenbosch University, Capetown, 7602, South Africa \\ ${ }^{2}$ Department of Social and Health Sciences, Millennium University, Blantyre, 2797, Malawi \\ ${ }^{3}$ Department of Economics, Chancellor College, University of Malawi, Zomba, Malawi
}

V1 First published: 27 Feb 2020, 2:9

https://doi.org/10.35241/emeraldopenres.13468.1

Latest published: 27 Feb 2020, 2:9

https://doi.org/10.35241/emeraldopenres.13468.1

\begin{abstract}
The paper investigates whether cultural lineage mediates gender gaps in child nutrition. It captures nutrition using height-for-age and stunting. The analysis uses the 2014 Malawi Millennium Development Goals Endline Survey data. We find evidence of male child nutrition deprivation in matrilineal cultural lineage. The gender of the household head does not relate to the mediating role of lineage on gendered nutrition gaps. As such, the analysis of gendered nutrition should account for the potential impact of culture to produce policy relevant estimates. Furthermore, deficiencies in male nutrition remains a strong health problem, particularly in cultures that benefit most from returns on female children. In these cultures, lineage dominates personal parental preferences. Therefore, there is a need to revisit received wisdom that providing more resources to female heads eliminates gender gaps by provision of culture-tailored nutritional interventions.
\end{abstract}

\section{Keywords}

Child Nutrition, Cultural Lineage, Malawi

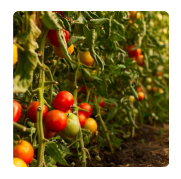

This article is included in the Sustainable Food

Systems gateway.

\section{Open Peer Review}

\begin{tabular}{cccc} 
Approval Status & $?$ \\
& 1 & 2 & 3 \\
\hline version 1 & $?$ & & \\
27 Feb 2020 & view & view & view
\end{tabular}

1. Aakanksha Sinha (iD), Seattle University, Seattle, United States

2. Nicola Desmond (D), Liverpool School of Tropical Medicine, Liverpool, United Kingdom

3. Sandra Jumbe, The London School of Medicine and Dentistry, London, United Kingdom

Any reports and responses or comments on the article can be found at the end of the article. 
Corresponding author: Martin Limbikani Mwale (martinresearch@gmail.com)

Author roles: Mwale ML: Conceptualization, Data Curation, Formal Analysis, Methodology, Software, Validation, Writing - Original Draft Preparation, Writing - Review \& Editing; Kamninga TM: Conceptualization, Data Curation, Formal Analysis, Methodology, Validation, Visualization, Writing - Original Draft Preparation, Writing - Review \& Editing; Cassim L: Writing - Review \& Editing

Competing interests: No competing interests were disclosed.

Grant information: The author(s) declared that no grants were involved in supporting this work.

Copyright: (c) 2020 Mwale ML et al. This is an open access article distributed under the terms of the Creative Commons Attribution License, which permits unrestricted use, distribution, and reproduction in any medium, provided the original work is properly cited.

How to cite this article: Mwale ML, Kamninga TM and Cassim L. Gender gaps in child nutrition in Malawi: Does cultural lineage matter? [version 1; peer review: 2 approved, 1 approved with reservations] Emerald Open Research 2020, 2:9

https://doi.org/10.35241/emeraldopenres.13468.1

First published: 27 Feb 2020, 2:9 https://doi.org/10.35241/emeraldopenres.13468.1 


\section{Introduction}

Gender gaps in child nutrition remain of interest to both researchers and policy makers. These disparities are important particularly because they determine both short-term and longterm gender differences in general health of individuals that affect wellbeing. Good nutrition reduces the risk of infection and mortality amongst children (Letois et al., 2016). It also leads to decent cognitive development, which enhances school performance (Alderman et al., 2006). The superior school outcomes culminate into employment in high-paying jobs within the labour market (Cunha \& Heckman, 2008). These positive outcomes entail that unattended gender differentials in child nutrition could lead to permanent welfare differences between males and females.

Literature in gendered nutrition finds conflicting evidence on the direction of bias. Studies conducted in Asia (Babu et al., 1993; Dasgupta, 2016; Lancaster et al., 2006) show that male children receive disproportionately more investment in nutrition relative to female children, while evidence from sub-Saharan Africa (Chirwa \& Pe Ngalawa, 2008; Garrett \& Ruel, 1999; Mussa, 2015) shows that girls enjoy a nutritional premium relative to boys. Reasons for the disparities can be summarised into preferences driven by equity and efficiency hypotheses (Behrman, 1988; Park \& Rukumnuaykit, 2004). The equity stream assumes that genders convert resources to child nutrition indicators such as height-for-age at a different rate and have different optimal nutrition requirements. Therefore, parents who seek to equate investment amongst their children lead a particular gender, whose optimal nourishment threshold is higher, into low nutrition (Dancer et al., 2008). The efficiency hypothesis postulates that parents could consciously invest more into the gender that provides them the highest returns (Dasgupta, 2016).

Could the efficiency hypothesis explain the female nutrition premium puzzle observed in sub-Saharan African literature? This paper exploits cultural lineage to investigate if parents make gender biased nutrition investments to children as a form of old age insurance using data from Malawi. The study seeks to establish if the efficiency hypothesis could explain the girl nutrition premium consistently found in sub-Saharan Africa. Firstly, we disaggregate Malawian tribes into matrilineal and patrilineal lineage and estimate gendered nutrition in the two subsamples. Results show that a male child is at a nutrition disadvantage in matrilineal tribes relative to patrilineal tribes. Secondly, we investigate if gender of the household head can exacerbate or reduce the lineage contingent gendered nutrition gaps. We find that gender of the head does not relate to the gendered nutrition mediation role of cultural lineage.

These results are particularly important in sub-Saharan Africa because matrilineal lineage dominates the region ${ }^{1}$. In Malawi, the lineage provides disproportionate weight of authority and custody of property and children in favour of a woman and her brothers (Kings, 2009). A man is supposed to leave his

\footnotetext{
${ }^{1}$ See 'Vusi Moloi (2012):The organic roots of the African matrilineal society.: www.africaunbound.org
}

original home and settle for marriage at the woman's village and all proceeds from their marriage remain invested in the woman's home area (Peters, 2010). The woman becomes a primary caretaker of her parents at their old age. On the contrary, the patrilineal lineage demands women to settle at a man's village and the man becomes the main owner of children and property in the home for married couples (Berge et al., 2014). Furthermore, the man is the principal caretaker of his parents at their old age (Chikhungu et al., 2014). Therefore, there is a direct advantage for parents investing much in a gender that supports them at their old age, as a form of old age insurance, in alignment to these lineage values. This becomes convenient particularly for rural economies like those of sub-Saharan Africa, where formal insurance markets exclude the majority of the population.

We therefore conclude that lineage old age insurance, a form of parental implicit expected discounted returns from investing in children, mediates gender gaps in child nutrition. Furthermore, under strong lineage, the sex of the household head, -a measure of autonomy in decision-making, fails to curb gendered nutrition disparities. The results call for studies to incorporate culture lineage aspects of child health investment in nutrition analyses. On the policy anterior, generic interventions, aiming at increasing household resources or rearranging power balance inside the household, could be ineffective at solving gendered malnutrition under strong cultural lineage. As such, curbing nutrition gaps in rural economies that have strong cultural ties demands policy that directly targets children irrespective of gender such as school feeding programmes.

\section{The child nutrition situation in Malawi}

Malawi remains one of the countries facing acute undernourishment despite the country's committed efforts to improve the ailment. For instance, Malawi ranks third on the Hunger and Nutrition Commitment Index; boasts of an affiliation to Scaling up Nutrition movement; and is amongst the few countries that meet the Maputo Declaration of directing 10\% public expenditure to agriculture (Gelli et al., 2017). For the past two decades, the country has experienced a reduction in wasting (low weightfor-height below -2 standard deviations); and underweight (low weight-for-age below -2 standard deviations). However, there less improvement in stunting (low height-for-age below -2 standards deviations).

Table 1 shows the malnutrition deficiency trends for Malawi, spanning from 1992 to 2014. Stunting and wasting remained Table 1. Trends in nutrition deficiencies amongst
children under five in Malawi 1992-2014.

\begin{tabular}{|l|r|r|r|r|r|}
\hline Deficiency & 1992 & 2000 & 2004 & 2006 & 2014 \\
\hline Stunting (\%) & 48.7 & 49 & 47.8 & 46 & 42 \\
\hline Wasting (\%) & 5.4 & 5.5 & 5.2 & 3.5 & 3.8 \\
\hline Underweight (\%) & 27.2 & 25.4 & 22 & 22 & 16.7 \\
\hline
\end{tabular}

Source: Mussa (2015) and NSO (2014) 
high from 1992, peaking in 2000, while the proportion of underweight reduced within the same time. In this period, the country experienced persistent droughts and a consequent poor food production that resulted in worsening of nutrition outcomes (Chirwa \& Pe Ngalawa, 2008). In response to food insecurity, the government introduced a farm input subsidy programme that allowed smallholder farmers to access inputs at a cost less than market price (Harrigan, 2008). All nutrition indicators improved in the year 2004, leading to further reduction in stunting and wasting but with no change in underweight at the year 2006. It is worth noting that in the year 2005, the country experienced a widespread expansion of the farm input subsidisation. Authors (Harou, 2018; Karamba \& Winters, 2015) find positive effects of the inputs programme on nutrition in children under five. Furthermore, the Malawi government adopted an antenatal care program, the focussed antenatal care (FANC) model, in 2005 that amongst its components, provides nutrition advice to pregnant women that could have positive spill over effects on new-born nourishment (Yoder et al., 2015). The FANC arguably contributed to the last drop in stunting and underweight between the years 2006 and 2014. Besides, the period also experienced an increase in wasting, although this did not return to the high pre-2000 level.

A notable concern in the way in which malnutrition has evolved over time is the persistence of stunting over the years. Mussa (2014) reveals that the problem is acute in the rural areas of the country. He further shows that low height-for-age is more prevalent amongst male children relative to females. Chirwa \& Pe Ngalawa (2008) find similar evidence of male child deprivation. As such, the effectiveness of policy to curb gendered malnutrition in general, and stunting in particular, demands a comprehensive understanding of the determinants of nutrition in the under-fives and the transmission mechanisms that mediate the undernourishment.

\section{Conceptual framework}

The paper models gender gaps in nutrition using a standard household utility maximisation framework suggested by Behrman \& Deolalikar (1988) and Strauss \& Thomas (1998). These authors present child nutrition an element in a household production function that also comprises purchases on food and non-food items, own produced food and leisure. A household maximises joint utility from the nutrition of all members. In this paper, we adapt the framework and present joint household utility as a function of child nutrition, $N$, and the rest of the household utility enhancing factors $1-N$ captured as

$$
U_{H}=f_{H}(N, 1-N)
$$

We track the first-order condition (FOC) of household utility with respect to nutrition status of a child as

$$
U_{N}=u_{i t}+u_{i t+1}
$$

We assume that the FOC comprises two additive components. The first is changes in utility from contemporary child nutrition returns to caretakers

$$
u_{i t}=R_{i t}
$$

In practice, this component could entail happiness from raising a health child and saving on illness expenditure. Assuming caretaker rationality, this component should always be greater than zero. The second part of the FOC represents changes in household utility as a function of variations in the discounted future returns from investment in child nutrition presented as

$$
u_{i t+1}=\beta \sum_{t=0}^{T} E\left(R_{i t+1}\right)
$$

The present value of future returns also depends on a discount factor - a measure of patience for the household. We assume a constant discount factor such that the utility differences result from variations in the returns from the genders. If in future, a male and female child differ in their provision of parental assistance then utility for this component could be greater than zero or less than zero based on the selected gender. These two components allow us to construct two propositions about the likely nutrition investment behaviour by caregivers.

$$
\text { Proposition A: } u_{i t}>0 \text { and } u_{i t+1}>0
$$

Under this proposition, the chosen gender positively benefits caretakers in both contemporary and inter-temporal periods. If this is true for both genders parents would invest more in the child that gives the highest total utility leading to a positive relationship between its gender and child nutrition.

$$
\text { Proposition B: } u_{i t}>0 \text { and } u_{i t+1}<0
$$

Proposition B entails low discounted returns from a particular gender relative its alternative resulting in disutility at the point of investment. The nutrition investment behaviour of caretakers could depend on the relative weight between contemporary and future expected returns. Parents are more likely to support both genders equally if there is no overall difference between the total utility derived from the genders. Alternatively, caretakers could biasedly invest in a gender whose discounted utility is large leading to high total utility relative to the other.

\section{Estimation strategy}

In rural economies where cultural values determine the amount of support that children provide to their parents at old age, the discounted future returns from a particular gender could arguably be systematically different. Lineage to these cultural values may therefore make caretakers non-randomly allocate nutrition investment in favour of the gender that is more likely to support them in future, as a form of old age insurance. 
We therefore use cultural lineage, defined in this context as matrilineal and patrilineal, to model a relationship between gender and nutrition (height-for-age) of children under five. We partition the sample into matrilineal children, those with values that women take care of their parents, and patrilineal children, those that confine parental care to men. We represent the estimated function as

$$
H A Z_{i h}=\alpha_{0}+\alpha_{1} \text { Male }_{i h}+\alpha_{2} X_{i j h}+\alpha_{3} \text { Com }_{i}+\varepsilon_{i j h}
$$

In Equation 2, we present nutrition using height-for-age score as a dependent variable. Height-for-age captures long-tern linear growth that is a summary of permanent investment in child nutrition. We prefer this indicator over alternatives, such weight for age and weight for height, because height-for-age does not fluctuate over-time. The alternative indicators vary with reasons beyond caretaker's investment such as seasonality of food availability and stress of the child during the period when survey take the child nutrition indicators measurements. We compute the height-for-age $\mathrm{z}$-score using the standard World Health Organisation anthro06 instrument. This instrument presents the indicator as

$$
H A Z_{\text {ih }}=\frac{\left(\text { Height }_{\text {ih }}-\text { Height }_{r}\right)}{S D_{\text {Height }_{r}}}
$$

In Equation 3, we model height-for-age as function of the difference between heights of child $i$ in household $h$ and the median height of a reference international group of children with the same age as the child. A z-score close to zero entails that the child is within the reference category while that below zero shows that the child is malnourished. Furthermore, a z-score of less than two standard deviations shows that the child is stunted - a malnutrition condition where an individual is too short for their age. Stunted children have visible malnutrition deficiencies such as anxiety, depression and low self-esteem (Walker et al., 2007). Caretakers' tolerance to such child undesirable characteristics also makes stunting a proxy for contemporary satisfaction with having a health child. We therefore include stunting models in addition to the height-for-age. Furthermore, stunting captures the severity of the lineage association with gendered nutrition gaps.

The variable of interest in Equation 2 is Male, which represents the gender of the child as a dummy with female child as a reference omitted group. The coefficient on the gender variable tells us if a particular lineage favours males over females. If we find a positive and significant coefficient, then males receive better nutrition investment relative to females under that particular cultural lineage.

Sahn \& Stifel (2002) show that child nutrition investment in a particular gender at times follows the gender of the household head. Male heads are more likely to favour male children and female children could be favouring female children. Therefore, in a culture where parents benefit much from a specific gender of children at their old age, parental natural preferences of a particular gender could counter the lineage effects if the two preferences oppose each other. On the other hand, aligned natural preferences and cultural values could exacerbate the lineage effects. For example, if lineage supports girls in a household headed by a woman who also favours female children, boys could be receive disproportionally low nutritional investment because girls get support from both household head preference and cultural values. However, it also possible for girls to get better nutrition investment in households headed by women through the equality hypothesis. A woman would use her empoweredhead position to provide equal nutrition investment to both genders. We therefore re-estimate Equation 2 by adding head of household and its interaction with child gender in Equation 4 to understand if being a male head mediates the relationship between gender of a child and child nutrition under the two lineages.

$H A Z_{i h}=\alpha_{0}+\alpha_{1}$ Male $_{i h}+\alpha_{2}$ Headgender $_{h}+\alpha_{3}$ Male $^{*}$ Headgender $+\alpha_{4} X_{i j h}+\alpha_{5}$ Com $_{i}+\varepsilon_{i j h}$

If the interaction term between the male child and male head of household is positive, then male heads favour male children under a particular lineage. If the lineage is pro-female, then male heads assist in reducing nutrition gaps between genders. If the lineage is pro-male, it entails that male heads perpetrate nutrition inequalities. The non-interacted head of household gender variable in the equation shows whether being a male head leads to improved nutrition of both child genders relative to when one is a female head.

Comparing nutrition outcomes across genders, mediated by lineage, requires unifying characteristics of the sampled children to allow unbiased comparison at the level of observables. We therefore include control variables represented by a vector of characteristics $X_{i j h}$. These attributes could be confounding the relationship of interest when omitted in the estimation.

The study therefore includes child specific characteristics. For instance Caregivers could apply more effort in caring for younger children relative to the older children due to the knowledge that infants have delicate lives that require more attention in their first years of life for survival (Sankar et al., 2015). Dancer et al., (2008) affirm that male children are more prone to infant deaths than females. Therefore, we anticipate nutrition will deteriorate with age and include it as a control variable. Nevertheless, the opposite could be true as older children can fetch for their own resources; for instance, obtaining food in addition to that provided by caretakers, giving them a nutritional premium over infants.

In addition, we include household-specific characteristics. For example, the number of siblings under the age of 17 potentially affects the nutrition status of a child. More siblings of this age group would imply increase in competition for childcare resources. The number of children becomes an estimation problem in instances where the increase is due to gender preferences of the parents. For instance, Hu \& Schlosser (2012) show that parents continue to bear children if they only have females until they get a male child. This may result in intense competition amongst female children for resources and resultant poor female nutrition. Education of the mother remains another 
contested determinant of child nutrition. While Alderman \& Headey (2017) find that educated mother have better nourished children, Sahn \& Stifel (2002) finds that the distribution of resources skews towards a single gender depending on the study location. Therefore, mothers' education could have disproportionate effects on gendered child nutrition and affect the relationship of interest if excluded in the models. Religion could also lead to different genders receive differential treatment leading to nutrition gaps. For instance, Klingorová \& Havlíček (2015) show that non-religious societies allow more balanced resource distribution by gender unlike religious societies that preserve male superiority. Income also stems as another important correlate of child nutrition. Björkman-Nyqvist (2013) found that gender gaps worsen in times of low income. Hence, more household income could imply an increase in availability of resources for all children, which has potential to lessen the pressure of rationing care in favour of a particular gender.

Furthermore, we include community fixed effects, particularly water and sanitation conditions. Dancer et al., (2008) show that infant mortality differs by gender. It is also possible that the minimum hygiene requirements differ between male and female children. Therefore, the usage of unsafe water and poor toilet facilities could be conveying itself as gender gaps perpetrated by intentional caregiver preferences when it is actually the genetic differences in tolerance to poor hygiene conditions. Finally, the paper also includes regional fixed effects to control for all other observed and unobserved spatial factors that could disproportionally affect the nutrition status of the child across gender.

\section{Data and descriptive statistics}

The paper uses data from the 2014 Malawi Millennium Development Goals Endline Survey (MES), conducted by the country's National Statistical Office (NSO) (for full description of the MES data see "The Malawi Millennium Development Goals Endline Survey Report, 2014" at https://www.nsomalawi.com). In this data, we assessed how height-for-age differs across genders; therefore, we compute the height-for-age z-scores and classify children under five by gender. Furthermore, we classify the households in which the children live into male headed and female headed as well as their culture into matrilineal and patrilineal lineage. We use Stata version 16 to clean the data and conduct the analysis. We estimated all models of the data using the Ordinary Least Squares technique.

The MES forms part of the Multiple Indicator Cluster Surveys (MICS) designed to provide estimates on the welfare of children and women at national, regional and district level. The survey covers 27 districts of Malawi and is nationally representative. It uses a two-stage sampling procedure with urban and rural areas in each of Malawi's three regions, the northern, central and southern, as the main sampling strata. After randomly selecting 1140 Enumeration Areas (clusters) within the strata the survey randomly selected 25 households within each cluster. This resulted in a sample of 28,479 households. The questionnaires of the survey collected information on all women aged 15-49 and men aged 15-49 in every third household on the interview series. The survey further sampled 19,285 children to collect information on child anthropometric measurements with a response rate of $98 \%$ within the interviewed households. After cleaning the data, which involved removing children with missing anthropometrics, excluding those with biologically implausible values and missing characteristics we ended up with an estimable sample of 17,768 children.

The MES collects information about the tribe of the head of households. We classify the tribes into two lineage categoriesmatrilineal and patrilineal following Berge et al., (2014). Figure 1 presents the distribution of malnutrition across gender and tribal lineage. We use the World Health Organisation (WHO) classification of malnutrition to compute mild stunting as children whose height-for-age is below minus one, moderate stunting for children with height-for-age that is below minus two and severe malnutrition for children whose heightfor-age is below minus three. The percentage of stunted males is higher than that of females under both cultural lineages. Overall, patrilineal children have better nutrition relative to matrilineal children. In terms of moderate stunting, both lineages have $3 \%$ more boys stunted relative to girls. Moderate stunting shows that $4 \%$ more patrilineal boys are stunted relative to their girls while the gap in matrilineal is $7 \%$. For severe stunting patrilineal boys have $7 \%$ more stunted boys in comparison to girls while the gap in matrilineal is $4 \%$.

Table 2 presents the descriptive statistics of the variables used in the paper. We disaggregate the statistics by culture lineage, giving the matrilineal and patrilineal categories. There is gender balance in the matrilineal at $50 \%$ while patrilineal has $51 \%$ male and $49 \%$ female children. Average height-for-age in the matrilineal is -1.75 and $40 \%$ of the children are stunted while the average height-for-age is -1.64 for patrilineal with $37 \%$ of the children student. The average age for the matrilineal sample is 2.01 years while that of the patrilineal is 2.02 years and the matrilineal children have fewer younger siblings (3.10) of the age 1-17 than the patrilineal children (3.27). The gender of household head is $79 \%$ male for matrilineal and $81 \%$ male for patrilineal. Matrilineal mothers are less educated and reside in poor households relative to the patrilineal mothers who are more educated and live in relatively richer households. In terms of sanitation and hygiene, $16 \%$ of matrilineal households use piped water and $0.01 \%$ use flush toilets against $20 \%$ of patrilineal households using piped water and $0.02 \%$ having flush toilets.

\section{Empirical findings}

The relationship between gender and child nutrition across lineage

To estimate the relationship between gender and child nutrition across lineage we partition the sample into matrilineal and patrilineal households. Table 3 provides results for the models. The first two columns use height-for-age as the dependent variable. Consistent with Mussa (2015) and Chirwa \& Pe Ngalawa (2008) we find that boys have poor nutrition relative to girls. Particularly, matrilineal boys are 0.199 standard deviations worse off relative to girls, while in patrilineal culture boys are 0.147 standard deviations poorer in nutrition relative to girls. These 


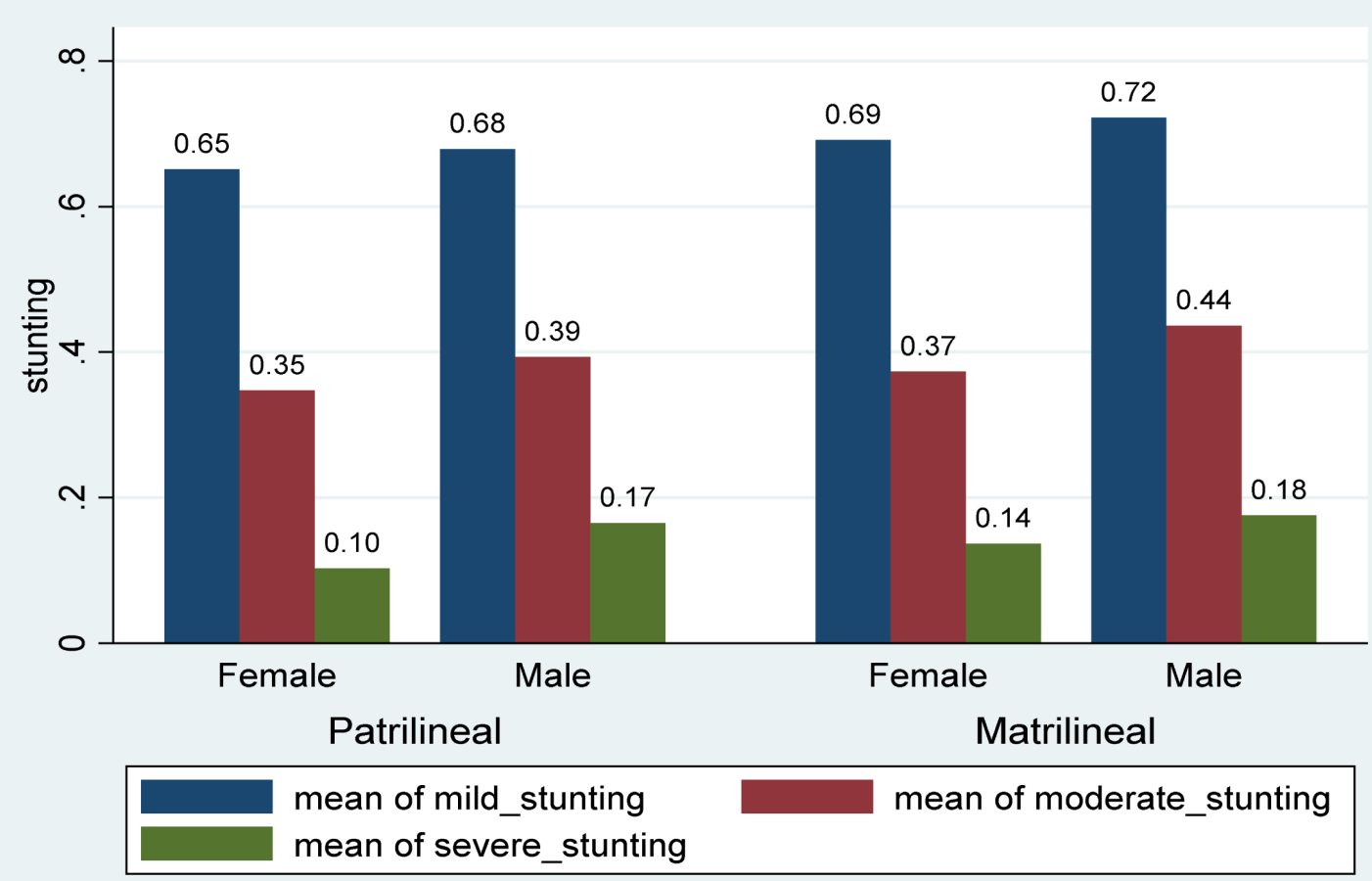

Authors own calculations using WHO classification

Figure 1. The distribution of malnutrition across gender and lineage.

Table 2. Summary statistics.

\begin{tabular}{|c|c|c|c|c|c|}
\hline \multirow{2}{*}{$\begin{array}{l}\text { Lineage } \\
\text { Variables }\end{array}$} & \multicolumn{2}{|c|}{ Matrilineal } & \multicolumn{2}{|c|}{ Patrilineal } & \multirow[b]{2}{*}{ Difference } \\
\hline & mean & SD & mean & SD & \\
\hline Male child & 0.50 & 0.50 & 0.51 & 0.50 & 0.01 \\
\hline Height-for-age & -1.75 & 1.44 & -1.64 & 1.42 & $0.11^{\star \star \star}$ \\
\hline Stunting & 0.40 & 0.49 & 0.37 & 0.48 & $-0.03^{\star \star \star}$ \\
\hline Child Age & 2.01 & 1.39 & 2.02 & 1.39 & 0.01 \\
\hline Number of children 1-17yrs. & 3.10 & 1.72 & 3.27 & 1.94 & $0.16^{\star * *}$ \\
\hline Male head & 0.79 & 0.40 & 0.81 & 0.39 & $0.02^{*}$ \\
\hline Uneducated mother & 0.14 & 0.34 & 0.11 & 0.31 & $-0.03^{\star \star \star}$ \\
\hline Primary mother & 0.71 & 0.45 & 0.67 & 0.47 & $-0.04^{\star * \star}$ \\
\hline Secondary mother & 0.14 & 0.35 & 0.20 & 0.40 & $0.06^{\star * *}$ \\
\hline Higher mother & 0.01 & 0.10 & 0.01 & 0.12 & $0.00^{\star}$ \\
\hline Chewa & 0.40 & 0.49 & 0.00 & 0.00 & $-0.40^{\star \star \star *}$ \\
\hline Tumbuka & 0.00 & 0.00 & 0.47 & 0.50 & $0.47^{\star * *}$ \\
\hline Lomwe & 0.25 & 0.43 & 0.00 & 0.00 & $-0.25^{\star \star \star}$ \\
\hline Tonga & 0.00 & 0.00 & 0.16 & 0.37 & $0.16^{* * *}$ \\
\hline Yao & 0.19 & 0.39 & 0.00 & 0.00 & $-0.19^{* \star *}$ \\
\hline Sena & 0.00 & 0.00 & 0.27 & 0.44 & $0.27^{\star \star \star}$ \\
\hline Nkhonde & 0.00 & 0.00 & 0.08 & 0.27 & $0.08^{\star * *}$ \\
\hline Ngoni & 0.16 & 0.37 & 0.03 & 0.16 & $-0.14^{\star \star \star}$ \\
\hline
\end{tabular}




\begin{tabular}{|c|c|c|c|c|c|}
\hline \multirow{2}{*}{$\begin{array}{l}\text { Lineage } \\
\text { Variables }\end{array}$} & \multicolumn{2}{|c|}{ Matrilineal } & \multicolumn{2}{|c|}{ Patrilineal } & \multirow[b]{2}{*}{ Difference } \\
\hline & mean & SD & mean & SD & \\
\hline Catholic & 0.18 & 0.39 & 0.13 & 0.34 & $-0.05^{\star \star \star}$ \\
\hline Protestant & 0.58 & 0.49 & 0.83 & 0.37 & $0.25^{\star \star \star}$ \\
\hline Muslim & 0.19 & 0.39 & 0.01 & 0.11 & $-0.18^{* * *}$ \\
\hline No-religion & 0.04 & 0.20 & 0.02 & 0.15 & $-0.02^{\star \star *}$ \\
\hline North & 0.02 & 0.14 & 0.62 & 0.49 & $0.60^{\star \star \star}$ \\
\hline Central & 0.44 & 0.50 & 0.10 & 0.30 & $-0.34^{\star \star \star}$ \\
\hline South & 0.54 & 0.50 & 0.28 & 0.45 & $-0.26^{\star \star \star}$ \\
\hline Poorest & 0.25 & 0.43 & 0.14 & 0.35 & $-0.11^{\star \star \star}$ \\
\hline Second & 0.23 & 0.42 & 0.18 & 0.38 & $-0.05^{\star \star \star}$ \\
\hline Middle & 0.21 & 0.41 & 0.22 & 0.41 & 0.01 \\
\hline Fourth & 0.16 & 0.37 & 0.24 & 0.42 & $0.07^{\star \star \star}$ \\
\hline Richest & 0.14 & 0.34 & 0.20 & 0.40 & $0.06^{\star \star \star}$ \\
\hline Piped water & 0.16 & 0.37 & 0.20 & 0.40 & $0.04^{\star \star \star}$ \\
\hline Borehole water & 0.65 & 0.48 & 0.63 & 0.48 & -0.01 \\
\hline Protected well & 0.15 & 0.36 & 0.10 & 0.30 & $-0.05^{\star * *}$ \\
\hline Protected spring & 0.01 & 0.10 & 0.01 & 0.09 & 0.00 \\
\hline Tanker-Truck & 0.00 & 0.04 & 0.00 & 0.02 & 0.00 \\
\hline Surface water & 0.03 & 0.17 & 0.06 & 0.24 & $0.03^{\star \star \star}$ \\
\hline Flush & 0.01 & 0.11 & 0.02 & 0.15 & $0.01^{\star \star \star}$ \\
\hline Pit-latrine & 0.93 & 0.26 & 0.91 & 0.29 & $-0.02^{\star \star \star}$ \\
\hline No toilet & 0.06 & 0.24 & 0.07 & 0.25 & 0.01 \\
\hline Observations & 13757 & & 4011 & & \\
\hline
\end{tabular}

Source: Authors own calculations from MES 2014 data

\section{Table 3. Results of gender gaps in nutrition by lineage.}

\begin{tabular}{|c|c|c|c|c|}
\hline & (1) & (2) & (3) & (4) \\
\hline Lineage & Matrilineal & Patrilineal & Matrilineal & Patrilineal \\
\hline Variable & Height-for-age & Height-for-age & Stunting & Stunting \\
\hline \multirow[t]{2}{*}{ Male Child } & $-0.199^{\star * *}$ & $-0.147^{\star \star *}$ & $0.069^{* * *}$ & 0.030 \\
\hline & $(0.033)$ & $(0.054)$ & $(0.012)$ & $(0.023)$ \\
\hline \multirow[t]{2}{*}{ Child Age } & $-0.114^{* * *}$ & $-0.086^{\star \star *}$ & $0.031^{* * *}$ & $0.015^{\star *}$ \\
\hline & $(0.009)$ & $(0.021)$ & $(0.004)$ & $(0.007)$ \\
\hline \multirow[t]{2}{*}{ No of children $1-17$ years. } & $-0.025^{\star *}$ & -0.020 & $0.006^{*}$ & 0.006 \\
\hline & $(0.011)$ & $(0.016)$ & $(0.003)$ & $(0.005)$ \\
\hline \multirow[t]{2}{*}{ Mother primary education } & 0.022 & $0.168^{\star}$ & $-0.041^{* *}$ & 0.008 \\
\hline & $(0.057)$ & $(0.088)$ & $(0.016)$ & $(0.024)$ \\
\hline \multirow[t]{2}{*}{ Mother secondary education } & 0.077 & $0.243^{\star *}$ & $-0.076^{\star \star *}$ & -0.035 \\
\hline & $(0.071)$ & $(0.096)$ & $(0.021)$ & $(0.039)$ \\
\hline \multirow[t]{2}{*}{ Mother higher education } & $0.239^{*}$ & 0.524 & -0.053 & -0.131 \\
\hline & $(0.137)$ & $(0.318)$ & $(0.049)$ & $(0.084)$ \\
\hline
\end{tabular}




\begin{tabular}{|c|c|c|c|c|}
\hline & (1) & (2) & (3) & (4) \\
\hline Lineage & Matrilineal & Patrilineal & Matrilineal & Patrilineal \\
\hline Variable & Height-for-age & Height-for-age & Stunting & Stunting \\
\hline \multirow[t]{2}{*}{ Poor } & $0.128^{\star *}$ & 0.028 & $-0.048^{* * *}$ & -0.007 \\
\hline & $(0.057)$ & $(0.136)$ & $(0.015)$ & $(0.038)$ \\
\hline \multirow[t]{2}{*}{ Middle } & $0.140^{*}$ & 0.104 & $-0.033^{*}$ & -0.072 \\
\hline & $(0.072)$ & $(0.137)$ & $(0.017)$ & $(0.044)$ \\
\hline \multirow[t]{2}{*}{ Richer } & $0.256^{\star * *}$ & 0.200 & $-0.067^{* * *}$ & $-0.093^{\star * \star}$ \\
\hline & $(0.057)$ & $(0.127)$ & $(0.016)$ & $(0.030)$ \\
\hline \multirow[t]{2}{*}{ Richest } & $0.343^{* * *}$ & 0.207 & $-0.109^{* * *}$ & $-0.080^{*}$ \\
\hline & $(0.062)$ & $(0.144)$ & $(0.012)$ & $(0.045)$ \\
\hline \multirow[t]{2}{*}{ Protestant } & 0.037 & 0.063 & -0.023 & -0.016 \\
\hline & $(0.041)$ & $(0.079)$ & $(0.016)$ & $(0.030)$ \\
\hline \multirow[t]{2}{*}{ Muslim } & $0.183^{* * *}$ & $-0.489^{* * *}$ & -0.020 & 0.102 \\
\hline & $(0.044)$ & $(0.178)$ & $(0.017)$ & $(0.081)$ \\
\hline \multirow[t]{2}{*}{ No-religion } & $-0.257^{\star \star \star}$ & -0.124 & $0.093^{\star * \star}$ & $0.110^{*}$ \\
\hline & $(0.066)$ & $(0.141)$ & $(0.019)$ & $(0.058)$ \\
\hline \multirow[t]{2}{*}{ Central region } & -0.106 & 0.021 & $0.070^{*}$ & -0.014 \\
\hline & $(0.116)$ & $(0.076)$ & $(0.040)$ & $(0.019)$ \\
\hline \multirow[t]{2}{*}{ Southern region } & -0.049 & 0.070 & 0.049 & -0.017 \\
\hline & $(0.119)$ & $(0.091)$ & $(0.039)$ & $(0.025)$ \\
\hline \multirow[t]{2}{*}{ Borehole } & 0.033 & 0.003 & -0.014 & -0.019 \\
\hline & $(0.051)$ & $(0.103)$ & $(0.020)$ & $(0.033)$ \\
\hline \multirow[t]{2}{*}{ Protected well } & -0.033 & -0.103 & -0.031 & 0.053 \\
\hline & $(0.063)$ & $(0.186)$ & $(0.020)$ & $(0.047)$ \\
\hline \multirow[t]{2}{*}{ Protected spring } & -0.143 & 0.213 & 0.006 & $-0.178^{\star * *}$ \\
\hline & $(0.119)$ & $(0.285)$ & $(0.048)$ & $(0.065)$ \\
\hline \multirow[t]{2}{*}{ Tanker-truck } & $-0.398^{* * *}$ & -0.337 & 0.032 & -0.133 \\
\hline & $(0.113)$ & $(0.368)$ & $(0.085)$ & $(0.336)$ \\
\hline \multirow[t]{2}{*}{ Surface water } & 0.185 & -0.084 & -0.048 & 0.077 \\
\hline & $(0.155)$ & $(0.167)$ & $(0.045)$ & $(0.050)$ \\
\hline \multirow[t]{2}{*}{ Pit-ratline } & -0.059 & $-0.544^{* * *}$ & $0.113^{*}$ & $0.132^{* *}$ \\
\hline & $(0.330)$ & $(0.160)$ & $(0.066)$ & $(0.049)$ \\
\hline \multirow[t]{2}{*}{ No toilet facility } & -0.257 & $-0.849^{* * *}$ & $0.173^{* * *}$ & $0.232^{* * *}$ \\
\hline & $(0.310)$ & $(0.233)$ & $(0.060)$ & $(0.064)$ \\
\hline \multirow[t]{2}{*}{ Constant } & $-1.473^{* * *}$ & $-1.118^{* * *}$ & $0.240^{* * *}$ & $0.256^{\star * *}$ \\
\hline & $(0.360)$ & $(0.230)$ & $(0.078)$ & $(0.078)$ \\
\hline Observations & 13,094 & 3,814 & 13,620 & 3,985 \\
\hline R-squared & 0.035 & 0.043 & 0.030 & 0.034 \\
\hline
\end{tabular}

Standard errors in parentheses. ${ }^{* * *} p<0.01,{ }^{* *} p<0.05,{ }^{*} p<0.1$. 
results seem to indicate that the intra-household gender gaps in nutrition that favour females are severe in cultures where future females are more beneficial to their parents through old age support.

Looking at the control variables, we find that older children have poor nutrition in both lineage with the problem more pronounced in matrilineal lineage. Furthermore, increased number of children aged between 1 to 17 years in a household negatively relates to child nutrition in matrilineal but not in patrilineal lineage. In terms of mothers' education, nutrition improves amongst patrilineal children particularly for primary and secondary education levels, while amongst the matrilineal only high levels of education makes a difference in improving child nutrition. Income associates with improved child nutrition only in matrilineal lineage. These results could indicate that matrilineal tribes are relatively resource-constrained in comparison to patrilineal cultures. Hence, an increased number of younger siblings aged between 1 and 17 years faces intense competition for child raising resources. Furthermore, the availability of more resources makes a positive nutritional difference only in matrilineal lineages, while amongst patrilineal lineages, availability of better childcare practices learnt from a formal education institution or informal means due to high literacy can determine improvements in child nutrition better than income. Being a Muslim within matrilineal lineage associates with improved child nutrition while reducing the nutrition, when in patrilineal lineage relative to the omitted category catholic. Furthermore, those without religion have poorly nourished children only in matrilineal lineage. Using water from tanker-trucks as opposed to tap water positively associates with poor nutrition only in matrilineal lineage while poor toilet facilities relative to flush toilets leads to nutrition deterioration only in patrilineal tribes.

In columns 3 and 4 of Table 3 we extend the analysis of heightfor-age by modelling stunting. Stunting depicts the severity of the gender nutrition differentials mediated by lineage as it captures abnormally low height-for-age relative to the anticipated levels. As the stunted variable may have immediate negative nutrition outcomes on the child, it reveals caretaker tolerance to current child nutritional deficiencies. Results in column 3 reveal that being a male in matrilineal increases the probability of stunting by 0.069 . On the contrary, there is no evidence to conclude that patrilineal lineage children differ in stunting status by gender. These results, with reference to the height-for-age results, could mean that patrilineal tribes conform to lineage expectation only if the neglected gender does not fall into nutrition deficiency, while matrilineal lineage caretakers conform to cultural expectations even if it means leaving the neglected gender into nutrition deficiency.

In the stunting models, we adapt the same set of controls used in height-for-age estimations. We find that age remains a positive determinant of child nutrition and increased number of younger siblings reduces child nutrition. Education of the mother becomes important for matrilineal children while household income levels now become important for child nutrition in both lineages. Households that have no religion in both lineages raise children prone to stunting relative to catholic believers. Using water from springs relative to tap water increases the probability for stunting only in patrilineal while both lineages suffer from increased probability of stunting when using any other toilet facility relative to flush toilet units

The relationship between gender and child nutrition across lineage mediated by gender of the head of household

Parental references could be perpetrating lineage-mediated gender gaps in nutrition through household power balance. For instance, in cases where the head is a male, he prefers male children, and the household is within patrilineal lineage, boys could have disproportionally better nutrition relative to female children. Besides, if the head is male, he prefers male children, and the household has matrilineal lineage, the head could use his headship bargaining power to invest more in boys that counters cultural position to favour girls. The results could be reduced gender gaps in nutrition. The converse of the two scenarios could be true if the head is female. We investigate these scenarios in this subsection. All estimations in these models include the control variables used in the results in Table 3.

Table 4 provides results for male-headed households. We include an interaction term between the make head and male child to capture the caretaker gender preferences. We find that having a male head improves height-for-age in matrilineal tribes only. Nevertheless, the male head does not use his male position to favour boys in all lineages. Results on the gender of children reinforces earlier findings that male children are at a nutrition disadvantage and this time more vivid only in matrilineal tribes (Table 5).

We repeat the analysis in Table 4 by changing the gender of the head to female. We find no evidence of caretaker gender preferences amongst female-headed households in both lineages. Furthermore, we find that children female-headed households have poor nutrition relative to those in male-headed households of matrilineal lineage. The stunting models reinforce the results that female children receive better nutrition investment in matrilineal tribes relative to male children.

\section{Discussion and conclusion}

The paper sought to investigate if lineage, an implicit present value of cultural discounted returns on children to caregivers, mediates gender gaps in child nutrition. It captures lineage by matrilineal and patrilineal cultures, using data from Malawi. Consistent with child nutrition literature in sub-Sahara, we find that male children have poor height-for-age relative to females. The gap is larger in matrilineal cultural lineages, where traditional values regard female children as providers of their parents at old age relative to male children. It is arguably true that caregivers' anticipation of more future support from female children relative to male children compels them to invest much in the girls' nutrition as a form of old age insurance. This form 
Table 4. Results of gender gaps in nutrition by lineage mediated by male heads.

\begin{tabular}{|c|c|c|c|c|}
\hline & (1) & (2) & (3) & (4) \\
\hline Lineage & Matrilineal & Patrilineal & Matrilineal & Patrilineal \\
\hline Variables & Height-for-age & Height-for-age & Stunting & Stunting \\
\hline \multirow[t]{2}{*}{ Male Child } & $-0.145^{\star *}$ & -0.240 & $0.051^{*}$ & 0.030 \\
\hline & $(0.066)$ & $(0.164)$ & $(0.027)$ & $(0.043)$ \\
\hline \multirow[t]{2}{*}{ Male Head } & $0.124^{*}$ & 0.104 & -0.019 & -0.035 \\
\hline & $(0.071)$ & $(0.103)$ & $(0.019)$ & $(0.037)$ \\
\hline \multirow[t]{2}{*}{ Male head*male child } & -0.067 & 0.111 & 0.023 & 0.001 \\
\hline & $(0.064)$ & $(0.177)$ & $(0.024)$ & $(0.057)$ \\
\hline All controls included & Yes & Yes & Yes & Yes \\
\hline \multirow[t]{2}{*}{ Constant } & $-1.569^{* \star \star}$ & $-1.213^{\text {***}}$ & $0.254^{* \star *}$ & $0.286^{* * *}$ \\
\hline & $(0.355)$ & $(0.266)$ & $(0.079)$ & $(0.088)$ \\
\hline Observations & 13,094 & 3,814 & 13,620 & 3,985 \\
\hline R-squared & 0.036 & 0.045 & 0.030 & 0.034 \\
\hline
\end{tabular}

Standard errors in parentheses. ${ }^{* *} p<0.01,{ }^{* *} p<0.05,{ }^{*} p<0.1$.

Table 5. Results of gender gaps in nutrition by lineage mediated by female heads.

\begin{tabular}{|l|c|c|c|c|}
\hline & $(\mathbf{1})$ & $\mathbf{( 2 )}$ & $\mathbf{( 3 )}$ & $\mathbf{( 4 )}$ \\
\hline Lineage & Matrilineal & Patrilineal & Matrilineal & Patrilineal \\
\hline Variables & HAZ2 & HAZ2 & stunting & stunting \\
\hline Male child & $-0.211^{\star * *}$ & $-0.129^{* *}$ & $0.074^{* * *}$ & 0.031 \\
\hline Female head & $(0.032)$ & $(0.057)$ & $(0.010)$ & $(0.029)$ \\
\hline & $-0.124^{*}$ & -0.104 & 0.019 & 0.035 \\
\hline Female head*Male child & $(0.071)$ & $(0.103)$ & $(0.019)$ & $(0.037)$ \\
\hline & 0.067 & -0.111 & -0.023 & -0.001 \\
\hline All controls included & $(0.064)$ & $(0.177)$ & $(0.024)$ & $(0.057)$ \\
\hline & Yes & Yes & Yes & Yes \\
\hline Constant & $(0.009)$ & $(0.021)$ & $(0.004)$ & $(0.007)$ \\
\hline & $-1.445^{* * *}$ & $-1.109^{* *}$ & $0.235^{* * *}$ & $0.251^{* * *}$ \\
\hline Observations & $(0.364)$ & $(0.227)$ & $(0.078)$ & $(0.077)$ \\
\hline R-squared & 13,094 & 3,814 & 13,620 & 3,985 \\
\hline
\end{tabular}

Standard errors in parentheses. ${ }^{* * *} p<0.01,{ }^{* *} p<0.05,{ }^{*} p<0.1$.

of insurance becomes particularly important in rural economies, such as those in a majority of sub-Saharan Africa, where formal insurance remains inaccessible to the poor majority.

Besides height-for-age, the paper estimated the relationship between culture lineages and gendered stunting. In line with the results on height-for-age, we find stunted boys in matrilineal but not patrilineal lineages. The result reveals that the gender gaps in nutrition favouring girls are more pronounced in cultures that benefit most from female future returns. Furthermore, stunting could result in current negative outcomes on male children's health, such as frequent sickness. As such, the existence of stunted matrilineal but not patrilineal boys could indicate that under strong cultural lineage pressures, caregivers ignore present time nutrition deficiencies in favour of future returns on children. On the other hand, it is possible that patrilineal caretakers invest 
disproportionately in male children in attempting to secure their old age insurance, to a level of eliminating natural nutritional differences that suit female over males.

In addition, we investigate if parental gender preferences through household headship relate to the gendered lineage nutrition gaps. Results show that being a male or female head of household does not affect male child nutrition. The result could entail that cultural lineage dominates personal preferences for a particular child gender under strong cultures. As such, the gender of the household head does not help in either countering or exacerbating gendered nutrition gaps.

We therefore conclude that cultural lineage could be an important child nutrition mediator that contributes to the standard result of male child undernourishment in some rural economies. As such, the analysis of gendered nutrition should account for the potential impact of culture to produce estimates relevant to policy. Furthermore, gender difference in nutrition remains a serious health concern particularly in cultures that benefit most from returns on female children. In these cultures, lineage dominates personal parental preferences. Therefore, there is need to revisit the prevailing wisdom that providing more resources to female heads of households eliminates gender gaps by provision of culture tailored nutritional interventions. In addition, gender-unbiased programs, such as school feeding programs, should supplement generic nutrition programs that target households such as distribution of child food supplements through household heads. This shall minimise gender biased child nutrition investment.

\section{Data availability}

\section{Source data}

Malawi Multiple indicator survey data is available at the following website: http://ghdx.healthdata.org/record/malawi-multipleindicator-cluster-survey-2013-2014.

All parties wishing to access MICS datasets must first register as a MICS data user. Dataset access is granted for legitimate research purposes.
Alderman H, Headey DD: How Important is Parental Education for Child Nutrition? World Dev. 2017; 94: 448-464.

PubMed Abstract | Publisher Full Text | Free Full Text

Alderman $\mathrm{H}$, Hoddinott $\mathrm{J}$, Kinsey $\mathrm{B}$ : Long term consequences of early childhood malnutrition. Oxford Econ Pap. 2006; 58(3): 450-474.

Publisher Full Text

Babu SC, Thirumaran S, Mohanam TC: Agricultural productivity, seasonality and gender bias in rural nutrition: Empirical evidence from South India. Soc Sci Med. 1993; 37(11): 1313-1319.

PubMed Abstract | Publisher Full Text

Behrman JR: Nutrition, health, birth order and seasonality: intrahousehold allocation among children in rural India. J Dev Econ. 1988; 28(1): 43-62. PubMed Abstract | Publisher Full Text

Behrman JR, Deolalikar AB: Health and Nutrition. In: Chenery, H. and Srinivan, T.N., Eds., Handbook of Development Economics. Amsterdam, North Holland. 1988; 1: $631-711$.

Publisher Full Text

Berge E, Kambewa D, Munthali A, et al.: Lineage and land reforms in Malawi: Do matrilineal and patrilineal landholding systems represent a problem for land reforms in Malawi? Land Use Policy. 2014; 41: 61-69.

Publisher Full Text

Björkman-Nyqvist M: Income shocks and gender gaps in education: Evidence from Uganda. J Dev Econ. 2013; 105: 237-253.

Publisher Full Text

Chikhungu LC, Madise NJ, Padmadas SS: How important are community characteristics in influencing children's nutritional status? Evidence from Malawi population-based household and community surveys. Health Place. 2014; 30: 187-195.

PubMed Abstract | Publisher Full Text

Chirwa EW, Pe Ngalawa $\mathrm{H}$ : Determinants of child nutrition in Malawi. S Afr $J$ Econ. 2008; 76(4): 628-640.

Publisher Full Text

Cunha F, Heckman J: Formulating, Identifying and Estimating the Technology of Cognitive and Noncognitive Skill Formation. J Human Resources. 2008; 43(4): 738-782.

Publisher Full Text

Dancer D, Rammohan A, Smith MD: Infant mortality and child nutrition in Bangladesh. Health Econ. 2008; 17(9): 1015-35. PubMed Abstract | Publisher Full Text

Dasgupta S: Son Preference and Gender Gaps in Child Nutrition: Does the Level of Female Autonomy Matter? Rev Dev Econ. 2016; 20(2): 375-386.

Publisher Full Text
Garrett JL, Ruel MT: Are determinants of rural and urban food security and nutritional status different? Some insights from Mozambique. World Dev. 1999; 27(11): 1955-1975.

Publisher Full Text

Gelli A, Margolies A, Santacroce M, et al.: Improving child nutrition and development through community-based childcare centres in Malawi - The NEEP-IE study: study protocol for a randomised controlled trial. Trials. 2017; 18(1): 284 .

PubMed Abstract | Publisher Full Text | Free Full Text

Harou AP: Unraveling the effect of targeted input subsidies on dietary diversity in household consumption and child nutrition: The case of Malawi. World Dev. 2018; 106: 124-135.

Publisher Full Text

Harrigan J: Food insecurity, poverty and the Malawian Starter Pack: Fresh start or false start? Food Policy. 2008; 33(3): 237-249.

Publisher Full Text

Hu L, Schlosser A: Trends in prenatal sex selection and girls' nutritional status in India. CESifo Econ Stud. 2012; 58(2): 348-372.

Publisher Full Text

Karamba RW, Winters PC: Gender and agricultural productivity: Implications of the Farm Input Subsidy Program in Malawi. Agr Econ (United Kingdom). 2015; 46(3): 357-374.

Publisher Full Text

Kings $\mathrm{P}$ : Some Changes in the Matrilineal Family System among the Chewa of Malawi since the Nineteenth Century. Nineteenth Century. 2009; 24(2):

257-274.

Publisher Full Text

Klingorová K, Havlíček, T: Religion and gender inequality: The status of women in the societies of world religions. Morav Geogr Rep. 2015; 23(2): 2-11. Publisher Full Text

Lancaster G, Ray R, Maitra P: Gender Bias in Nutrient Intake: Evidence from Selected Indian States. 2006; 7(2): 255-299.

Publisher Full Text

Letois F, Mura T, Scali J, et al.: Nutrition and mortality in the elderly over 10 years of follow-up: the Three-City study. Br J Nutr. 2016; 116(5): 882-889. PubMed Abstract | Publisher Full Text | Free Full Text

Mussa R: A matching decomposition of the rural-urban difference in malnutrition in Malawi. Health Econ Rev. 2014; 4(1): 11. PubMed Abstract | Publisher Full Text | Free Full Text

Mussa R: Intrahousehold and interhousehold child nutrition inequality in malawi. S Afr J Econ. 2015; 83(1): 140-153.

Publisher Full Text 
NSO: Malawi MDG Endline Survey 2014. Zomba, Malawi: National Statistica Office (NSO). 2015

Reference Source

Park A, Rukumnuaykit P: Eat Drink Man Woman: Testing for Gender Bias in China Using Individual Nutrient Intake Data. Working Paper. 2004; 1-33. Reference Source

Peters PE: "Our daughters inherit our land, but our sons use their wives' fields": matrilineal-matrilocal land tenure and the New Land Policy in Malawi. $J$ East Afr Stud. 2010; 4(1): 179-199.

Publisher Full Text

Sahn DE, Stifel DC: Parental preferences for nutrition of boys and girls: Evidence from Africa. J Dev Stud. 2002; 39(1): 21-45.

Publisher Full Text

Sankar MJ, Sinha B, Chowdhury R, et al:: Optimal breastfeeding practices and infant and child mortality: a systematic review and meta-analysis. Acta Paediatr. 2015; 104(467): 3-13.

PubMed Abstract | Publisher Full Tex

Strauss J, Thomas D: Health, Nutrition, and Economic Development. J Econ Lit. 1998; 36(2): 766-817.

Reference Source

Walker SP, Chang SM, Powell CA, et al:: Early childhood stunting is associated with poor psychological functioning in late adolescence and effects are

reduced by psychosocial stimulation. $J$ Nutr. 2007; 137(11): 2464-2469.

PubMed Abstract | Publisher Full Text

Yoder PS, Nsabagasani X, Eckert E, et al:: Perspectives of health care providers on the provision of intermittent preventive treatment in pregnancy in health

facilities in Malawi. BMC Health Serv Res. 2015; 15(1): 354

PubMed Abstract | Publisher Full Text | Free Full Text 


\section{Open Peer Review}

\section{Current Peer Review Status:}

\section{Version 1}

Reviewer Report 24 June 2020

https://doi.org/10.21956/emeraldopenres.14538.r26847

(C) 2020 Jumbe $\mathbf{S}$. This is an open access peer review report distributed under the terms of the Creative Commons Attribution License, which permits unrestricted use, distribution, and reproduction in any medium, provided the original work is properly cited.

\section{Sandra Jumbe}

Centre for Primary Care and Public Health, The London School of Medicine and Dentistry, London, United Kingdom

Introduction - paragraph on efficiency hypothesis confusing as it reads like results i.e. results show that a male child is at nutrition disadvantage in matrilineal tribes, etc. Are you reporting previous study results or this study?

Under 'Estimation Strategy' check typing error i.e. 'Male heads are more likely to favour male children and female children could be favouring female children.'

Overall I find the conceptual framework of the study a bit oversimplistic. regarding the assumption that male heads would favour male children and vise versa. Also how does this work in households with children who are only girls or only boys?

Data source provided; www.nsomalawi.com. I assume this data is available to ensure full reproducibility.

The finding that boys have more stunting than girls in matrilineal cultures could go beyond values based notions. Perhaps matrilineal communities suffer more socio-economic disadvantage than patrilineal. Meaning less nutritional food to give to children regardless of gender. It is well known that boys require more food than girls to develop. But in a family setting I doubt a parent would want to be obviously seen giving more to the boy to accommodate this. So this may be a key factor besides cultural lineage and the concept of 'old age insurance'.

Is the work clearly and accurately presented and does it cite the current literature? Yes

Is the study design appropriate and is the work technically sound? Yes

Are sufficient details of methods and analysis provided to allow replication by others? 
Yes

If applicable, is the statistical analysis and its interpretation appropriate?

I cannot comment. A qualified statistician is required.

Are all the source data underlying the results available to ensure full reproducibility? Yes

Are the conclusions drawn adequately supported by the results?

Yes

Is the argument information presented in such a way that it can be understood by a nonacademic audience?

Yes

Does the piece present solutions to actual real world challenges?

Yes

Is real-world evidence provided to support any conclusions made?

Yes

Could any solutions being offered be effectively implemented in practice?

Yes

Competing Interests: No competing interests were disclosed.

Reviewer Expertise: Health psychology, child and adolescent mental health

I confirm that I have read this submission and believe that I have an appropriate level of expertise to confirm that it is of an acceptable scientific standard.

Reviewer Report 17 June 2020

https://doi.org/10.21956/emeraldopenres.14538.r26848

(c) 2020 Desmond N. This is an open access peer review report distributed under the terms of the Creative Commons Attribution License, which permits unrestricted use, distribution, and reproduction in any medium, provided the original work is properly cited.

\section{Nicola Desmond}

Department of International Public Health, Liverpool School of Tropical Medicine, Liverpool, United Kingdom

This interesting article examines whether child nutrition is impacted by cultural lineage as it is mediated through gender gaps. It asks whether matrilineal and patrilineal cultural systems impact on unequal distribution of nutrition amongst boys and girls. It finds that male child nutrition 
deprivation is exacerbated within societies with matrilineal cultural heritage, where parents perceive greater likelihood of return on female child investment than male. It also finds that a more equal nutrition distribution occurs within patrilineal societies, despite perceptions that investment in boys will yield greater return, perhaps due to modernising practices where structural gendered inequalities are increasingly less prevalent.

The paper provides an original perspective on socio-cultural factors underlying child nutrition disparities with a focus on Malawi where matrilineal heritage remains common amongst different ethnic groups. I am afraid I am not a trained economist and therefore am unable to comment on the statistical analysis but have reviewed the paper from a socio-cultural perspective as an anthropologist.

The paper does need a good proof read to correct some basic errors in language. The introduction is well written but the authors cite the results very early on in the paper - this may be common practice for economics papers, although not for other more Epi papers and might need addressing.

Otherwise I found the paper fascinating and an interesting contribution to work in understanding gendered child nutrition deficiencies.

Is the work clearly and accurately presented and does it cite the current literature? Yes

Is the study design appropriate and is the work technically sound? Yes

Are sufficient details of methods and analysis provided to allow replication by others? Yes

If applicable, is the statistical analysis and its interpretation appropriate?

I cannot comment. A qualified statistician is required.

Are all the source data underlying the results available to ensure full reproducibility? Yes

Are the conclusions drawn adequately supported by the results? Yes

Is the argument information presented in such a way that it can be understood by a nonacademic audience?

Yes

Does the piece present solutions to actual real world challenges?

Yes

Is real-world evidence provided to support any conclusions made?

Yes 


\section{Could any solutions being offered be effectively implemented in practice? Yes}

Competing Interests: No competing interests were disclosed.

Reviewer Expertise: Medical anthropology; risk perceptions; behaviour change ;treatment seeking; consequences of health technologies (intended and unintended)

\section{I confirm that I have read this submission and believe that I have an appropriate level of expertise to confirm that it is of an acceptable scientific standard.}

Reviewer Report 17 June 2020

https://doi.org/10.21956/emeraldopenres.14538.r26790

(C) 2020 Sinha A. This is an open access peer review report distributed under the terms of the Creative Commons Attribution License, which permits unrestricted use, distribution, and reproduction in any medium, provided the original work is properly cited.

\section{Aakanksha Sinha}

Seattle University, Seattle, WA, United States

The authors do a great job at shining light on an important and unique light of gender differences in child malnutrition with regard to male children in Malawai. It is definitely a topic that is not talked about much and requires more attention. More research has been done in the area of gaps in nutrition with regard to female children across the world. A few suggestions/ comments for the authors that could help strengthen the paper:

1. Grammar/ spellings - There are several grammatical and spelling errors throughout the paper. I would highly recommend looking through the paper carefully and fixing those.

2. Introduction section- Since this is a new/less known way of looking at gender disparities in child nutrition - I would recommend providing more context. In general literature on gender gaps in child malnutrition is focused female children being negatively impacted - therefore the authors should provide some context and statistics to prove why their lens is important. Also author indicates the use of height for age and stunting as measures. Both of these mean the same thing.

3. Statistics of male child malnutrition - Need more evidence and literature on male child malnutrition. The introduction section needs more clarity and information on deprivations of male children, and covariates that might be impacting the deprivations.

4. Analysis: The analysis section is well laid out, however the focus is not on cultural lineage and focuses on too many other factors. I would recommend focusing on gender gaps of child nutrition and then looking at the mediation model while controlling for all environmental factors.

5. Results description - this section needs more clarity. It gets confusing with regard to what 
the focus of the paper is. There is too much going on.

6. Implications/discussion/conclusion: This section also needs more clarity of why the study is important and how does it add to contextual knowledge of matriarchal societies in sub Saharan Africa. Local policy implications or tying it with the Sustainable Development Goals could help this area as well.

7. Overall - I think the paper needs significant work to clearly indicate why we need to pay attention to local contexts, understand cultural impacts on child nutrition and how deep rooted social norms impact household decisions - and then narrow it down to the context of Malawi which presents a unique context of male children being negatively impacted.

Is the work clearly and accurately presented and does it cite the current literature? Partly

Is the study design appropriate and is the work technically sound?

Partly

Are sufficient details of methods and analysis provided to allow replication by others? No

If applicable, is the statistical analysis and its interpretation appropriate? Yes

Are all the source data underlying the results available to ensure full reproducibility? Yes

Are the conclusions drawn adequately supported by the results? Partly

Is the argument information presented in such a way that it can be understood by a nonacademic audience?

Partly

Does the piece present solutions to actual real world challenges?

Partly

Is real-world evidence provided to support any conclusions made? Partly

Could any solutions being offered be effectively implemented in practice? Partly

Competing Interests: No competing interests were disclosed.

Reviewer Expertise: Food security, child malnutrition, global food security, program evaluation 
I confirm that I have read this submission and believe that I have an appropriate level of expertise to confirm that it is of an acceptable scientific standard, however I have significant reservations, as outlined above. 